\title{
MEMÓRIA, COMUNICAÇÃO E SAMBA: PARTILHAS DE UM MUNDO EM COMUM
}

\author{
Maria Livia de Sá Roriz Aguiar ${ }^{1}$
}

\begin{abstract}
Resumo
O texto procura mostrar a correlação entre memória e comunicação através da apresentação de fragmentos narrativos de alguns integrantes da Velha Guarda das Escolas de Samba do Rio de Janeiro, que constroem, a partir de múltiplos trabalhos memoráveis, estratégias que correlacionam o mundo do samba ao mundo de suas vidas. Num primeiro momento aborda teoricamente a questão da memória, para num segundo instante mostrar como os personagens dessa história (os idosos da Velha Guarda) constroem em atos de comunicação um mundo em comum: o universo do samba.
\end{abstract}

Palavras-chaves: Memória, comunicação, samba, Velha Guarda.

\begin{abstract}
This paper analyzes the correlation between memory and communication by presenting narrative of some members of the Velha Guarda of Samba Schools of Rio de Janeiro, which create, by using multiple memorable works, strategies that link the world of samba with their lives. First, this article tackles the question of memory theoretically; after that, it shows how the actors in this story (the elders of the Velha Guarda) create, in acts of communication, a world in common: the universe of samba.
\end{abstract}

Keywords: Memory, communication, samba, Velha Guarda.

\section{INTRODUÇÃO}

O objetivo desse artigo é mostrar como, através de trabalhos da memória (HALBWACHS, 2006), um grupo particular, no caso deste estudo os sambistas que fazem parte de uma associação que reúne os componentes da Velha Guarda das Escolas de Samba do Rio de Janeiro, constroem territórios de pertencimento que são reatualizados e ressignificados como lugar cultural.

A partir desse entendimento, a associação, criada por eles na década de 1980 para promover o fortalecimento do grupo, denominada Associação da Velha Guarda das Escolas de Samba do Rio de Janeiro (AVGESRJ), passa a ser território comum, onde constroem o si mesmo e os outros, emergindo momentos fundamentais de suas existências. Há um movimento continuado de produção de narrativas a partir dos trabalhos de memória que permitem a eles se instituírem como pertencentes ao mundo do samba. É dali que falam, é ali que se reconhecem, é nesse território (também de memória) que fabricam a linha de suas vidas.

Esse artigo será dividido em duas partes. Na primeira, além de conceituarmos teoricamente a questão da memória, estabeleceremos os nexos que fazem do corpo desses atores lugares privilegiados de sua ação de comunicação no mundo. Na segunda, através das entrevistas, mostraremos como a memória do grupo constrói um passado partilhado

\footnotetext{
${ }^{1}$ Psicóloga (Universidade Gama Filho), mestre em Psicologia Social (Universidade do Estado do Rio de Janeiro).
} 
que se institui como mundo comum. Esse mundo comum é também o mundo da comunicação partilhado por estratégias sensíveis (RANCIÈRE, 2009).

\section{Memória e comunicação: partilhando o sensível}

Lugares, restos, trabalhos, imagens, vestígios, farrapos são expressões com as quais diversos autores procuram conceituar a memória, sobretudo, nos últimos trinta anos (NORA, 1984; HALBWACHS, 2006; HUYSSEN, 2000; RICOEUR, 2008; POLLAK, 1989 e 1992; BOSI, 1994). Entretanto, a construção da questão teórica da memória é muito anterior.

Num longo debate que começa no início do século XX, repartiu-se numa visão que considerava a memória como pertencendo ao indivíduo e outra que introduz na sua definição a dimensão social. As reflexões de Sigmund Freud em "Repetir, recordar e elaborar" (1914) e em "Notas sobre o Bloco Mágico" (1924) foram inaugurais e fundamentais para a construção do conceito. Por outro lado, o sociólogo Maurice Halbwachs $(1925 ; 1939 ; 1950)$ acrescentou a dimensão social e coletiva como sendo indispensável para pensar a memória ${ }^{2}$.

Esse debate se acentua, sobretudo, a partir da década de 1980, quando outros autores acrescentam novas reflexões. É o caso, por exemplo, de Pierre Nora, que, em 1986, lança a coletânea Lugares de memória, em que no texto introdutório procura definir esses lugares ao mesmo tempo funcionais, materiais e simbólicos ${ }^{3}$.

Mas o debate maior ocorreu entre os autores contemporâneos (como Fredric Jameson, 2006), que enxergaram o mundo atual como um lugar de perda das referências históricas promovida pela aceleração do ritmo do tempo e pelas transformações tecnológicas, e aqueles que, ao contrário, defenderam a necessidade de memória da cultura contemporânea (HUYSSEN, 2000; COLOMBO, 1991).

Em linhas gerais e esquemáticas, podemos resumir a questão da memória em três postulados centrais: memória é reconstrução; memória é dinâmica e flexível e, finalmente, memória é do presente.

\footnotetext{
${ }^{2}$ Ao longo do texto, a referência à edição de A memória coletiva (1925) foi de 2006 (Editora Centauro). Sobre a primeira edição, cf. prefácio "Un demi-après as mort...", de Gérard Namer, In: HALBWACHS, M. (1997). O artigo "La mémoire collective chez les musiciens", incluído na edição de A memória coletiva, editada em 2006, no Brasil, é de 1939. Já a primeira edição dos Quadros sociais da memória é de 1950.

${ }^{3}$ Editada na França pela Gallimard a partir de 1984, a coletânea Les lieux de mémoire se subdivide em três partes (totalizando sete volumes): La Republique, La Nation (I, II e III) e Les France (I, II e III).
} 
Reconstruir nunca é recompor literalmente da forma como ocorreu. Os acontecimentos são únicos, existem naquele momento. Recordar implica em trazer à mente um acontecimento passado com as implicações do presente. Para melhor exemplificar, pode-se pensar na leitura de um livro. A primeira leitura acontecerá de uma maneira; iremos absorver os significados de uma forma. A segunda trará, além da lembrança da leitura anterior, opiniões e modos de pensar diferentes.

Explicando o mesmo processo, em relação aos acontecimentos midiáticos, Ana Paula Goulart Ribeiro (2007) acentua o fato de o passado ser flexível e o presente "um fluxo de mudanças constantes". "O senso comum, no entanto, costuma pensar o tempo como linear e o passado como fixo e imutável". Partindo do pressuposto de que os acontecimentos nunca são "pura factualidade", não há um fato passado único e previsível, há sempre trabalhos de memória reconstituindo a possibilidade de passado. As lembranças não são, remarca a autora, "uma linear repetição do passado". As mudanças são "constantemente geradas por contextos sociais diversos, que associam e selecionam o passado para preencher o presente de sentido e configurar o futuro" (p. 220-221).

Em segundo lugar, é necessário considerar a memória como dinâmica e flexível. Ela faz parte da constituição do indivíduo: é a consciência do si mesmo. Por isso, os conceitos de memória e identidade são imbricados. Identidade é memória em ato. Ao se falar em memória há quase que uma referência obrigatória à questão da identidade. Para alguns autores (CANDEAU, 2011; RICOEUR, 2008), memória e identidade estão indissoluvelmente ligadas.

Em terceiro lugar, é preciso considerar que memória é do presente, postulado central e dos mais importantes que deriva das ponderações de Halbwachs (2006). Para ele, a memória não era do passado, mas sempre do presente, já que se constituía em múltiplos trabalhos realizados no presente objetivando o passado.

A tradição dos estudos da memória seguem no século XX duas direções: a primeira constrói a sociologia da memória a partir das formulações inauguradas por Maurice Halbwachs (1925) e a segunda é dependente da tradição filosófica de Henri Bergson $(1990)^{4}$. Mas ambos dialogam diretamente com a psicanálise freudiana, uma vez que foi Freud, a partir do final do século XIX, que introduziu na clínica psicanalítica a necessidade de "recordar, repetir e elaborar" (1914).

\footnotetext{
${ }^{4}$ A edição de Matéria e memória citada neste texto é da Martins Fontes, de 1990. A primeira edição do livro, na França, é de 1896.
} 
$\mathrm{Na}$ teoria de Maurice Halbwachs podem ser visualizadas três proposições articuladas: o passado se conserva e se reconstrói a partir do presente; a memória do passado só é possível em função dos quadros sociais e existe uma função social na memória.

Para além dos mecanismos da memória, é preciso considerar que a memória coletiva se apoia em "notáveis", mediadores que controlam o acesso a ela. No caso da família, são os avós, os mais velhos, aqueles que desempenham um papel na memória coletiva familiar: eles são ao mesmo tempo mediadores no interior da família, religando as diferentes fases dessa memória coletiva, e mediadores para o exterior, religando a memória coletiva familiar à da sociedade.

No caso do grupo de velhos sambistas, aparece claramente esse papel de testemunhas privilegiadas de um passado vivido em comum. A idade avançada de cada um, uns mais outros menos, os transforma em testemunhas do passado do samba, em notáveis desse mundo, e é também nesse papel que eles fazem questão de ser reconhecidos. São eles que também constroem a si mesmos como testemunhas de uma memória coletiva do samba, e a criação da associação transforma-se, assim, num ato de instituição (BOURDIEU, 1989).

Da mesma forma, ao repetirem inúmeras vezes que são "baluartes" e "guardiões" do samba, estão construindo sua importância na hierarquia das escolas e do samba, tomando para si um lugar que só existe porque são testemunhas de um passado comum. Um passado que viveram e que também herdaram da memória de seus pais e seus avós. Um passado, por outro lado, que estão legando aos netos, bisnetos e tataranetos.

Muitas dessas memórias por ouvir dizer aparecem claramente nos testemunhos dos idosos da Velha Guarda ${ }^{5}$. Diversas são as referências ao tempo de perseguição ao samba, a forma como deviam correr da "cavalaria da Polícia", das "borrachadas" que levavam. Tomando em consideração a idade que possuem hoje, podemos concluir que o testemunho desse passado é, algumas vezes, um legado recebido dos antecessores.

Em relação à reflexão de Sigmund Freud, criador da psicanálise, sobre memória, no texto "Recordar, repetir e elaborar" (1914), a questão é apresentada nas entrelinhas, já que Freud não a cita diretamente, ao se referir, por exemplo, às "lembranças encobridoras". Depois de descrever, brevemente, as técnicas anteriores da psicanálise

\footnotetext{
${ }^{5}$ Para a realização da pesquisa, foram entrevistados 10 sambistas integrantes de diversas escolas de samba do Rio de Janeiro, todos pertencentes à Associação da Velha Guarda das Escolas de Samba do Rio de Janeiro. Foram entrevistados homens e mulheres com idade igual ou superior a 60 anos.
} 
(como a hipnose), enfatiza a arte da interpretação utilizada pelo analista para "identificar as resistências que lá [na mente do paciente] aparecem”, e torná-las conscientes para ele.

Memória para Freud é a dialética entre recordar e esquecer e repressão. Pela recordação, monta-se a história que figura numa lacuna. $\mathrm{O}$ recalcamento, ou seja, a produção de lembranças encobridoras ou lembranças não acionadas é o ato suposto mais importante para a questão da memória.

Em "Uma nota sobre o Bloco Mágico" (1924), a questão do esquecimento aparece como metáfora, construída em torno dessa tecnologia, bloco mágico, que apareceu no início do século XX. Nesse texto, Freud produz uma das mais importantes reflexões sobre a escrita, que liberta a lembrança para o esquecimento, ao se fixar ideias em suportes duradouros. Para ele, a escrita é um dos aparelhos auxiliares que "inventamos para a melhoria ou intensificação de nossas funções sensoriais [...] construídos segundo o mesmo modelo que os próprios órgãos dos sentidos ou parte deles” (FREUD, 1924). Esses dispositivos - a escrita, os óculos, as câmeras fotográficas, os aparelhos acústicos - auxiliam a memória, ainda que de maneira imperfeita, se comparados com o aparelho mental. Todos podem registrar traços mnêmicos de maneira permanente, o que produz a diferença deles em relação ao aparelho mental humano.

Conforme a duração do registro há, segundo Freud, dois tipos de memória: a duradoura, representada pela escrita que fixa no papel o texto de maneira permanente, ou seja, como rastro duradouro; e a que pode ser facilmente apagada. Aquilo que se escreve no quadro com giz, no texto de Freud, é a metáfora do que é lembrado e pode ser apagado e, portanto, está próximo do esquecimento.

No mesmo texto, estabelece aproximação entre a técnica da psicanálise e as possibilidades do brinquedo bloco mágico. Segundo a descrição de Freud, o bloco era uma tábua encerada que tinha a superfície preparada por um papel transparente e uma camada de celuloide. Quando se escrevia nela com um lápis ou um estilete, a escrita na cera podia ser apagada quando se erguia uma dessas coberturas. Mas, mesmo assim, continuavam no bloco os traços duradouros dessa escrita. Ao se colocar, por exemplo, o bloco contra a luz, os traços da escrita primitiva apareciam.

Nesses rastros duradouros, para Harald Weinrich, Freud faz uma analogia com o inconsciente. "Inconsciente é algo ex-sabido que foi esquecido, mas que nem por isso despareceu do mundo. Continua formando uma camada latente da alma, pois - assim diz um teorema fundamental da Psicanálise - na vida da alma nada se perde" (2001, p. 187188). 
Andreas Huyssen (2000) considera que se vive no mundo contemporâneo a explosão do memorável: a moda retrô, a edição de livros destacando personagens históricos, que rapidamente se transformam em best-sellers, a explosão de filmes de época, a proliferação de museus e outros santuários de memória mostram que se vive a sedução do memorável.

Estaria inaugurado um novo regime de memória através da multiplicação de espaços de rememoração, refletindo o desejo de ancorar um mundo marcado por crescente mobilidade e transformação, de forma a compensar a perda de elementos sólidos e concretos que antes serviam de referência aos sujeitos. A memória se inscreve em monumentos, museus, casas de culturas, bibliotecas, entre outros, considerados por Pierre Nora (1984) lugares que são criados com a finalidade de perpetuar a memória.

Michel Pollak (1989), por outro lado, ao destacar as possibilidades culturais e políticas da memória, se refere às memórias subterrâneas, silenciadas, enquadradas e marginalizadas, enfatizando também as possibilidades das memórias dominantes e dominadas. A fronteira entre o "dizível e o indizível, entre o confessável e o inconfessável”, para ele, é o que separa a memória de grupos específicos dominados e a memória coletiva organizada que uma sociedade majoritária ou o Estado desejam impor. É preciso, portanto, distinguir entre memórias dominantes e dominadas que podem se transformar em memórias silenciosas e subterrâneas, que, entretanto, podem um dia aflorar e de memória inaudível se converter em memória ruidosa, como enfatiza o autor.

Existe uma relação entre lembrar e esquecer que pode estar ligada à memória histórica. Assim como pode existir uma lembrança coletiva, há que se considerar muitas vezes a emergência de um esquecimento coletivo ou, como conceitua Pollak, uma memória subterrânea.

Para uma memória emergir, ser reconstruída, faz-se necessário o testemunho, que assim se constitui em espécie de prova de que se pode relembrar. As pessoas são testemunhas e os lugares testemunham, permitindo a construção da ideia de resgate da memória. É nesse sentido que os sujeitos dessa pesquisa são testemunhas não apenas de suas existências, mas de suas vidas no mundo do samba carioca. Como enfatiza Pollak, "há uma permanente interação entre o vivido e o aprendido, o vivido e o transmitido. E essas constatações se aplicam a toda forma de memória, individual e coletiva, familiar, nacional e de pequenos grupos $(1989$, p. 8$)$ ".

O trabalho de enquadramento da memória se dá também pela seleção daqueles que serão testemunhas. Podemos observar isso na história de maneira mais ampla, mas 
também na história contada por pequenos grupos, em que muitas vezes fica evidente a tentativa de controle de quem pode falar do passado. No caso do grupo estudado, não percebemos que houvesse por parte dos integrantes da Associação uma escolha deliberada de quem poderia falar. Eles sempre indicavam aqueles que consideravam terem mais experiência no mundo do samba. Talvez o fato de termos procurado a diretoria da Associação só ao final da pesquisa tenha sido a razão por não percebermos essa tentativa de escolher quem teria uma fala mais autorizada para falar em nome da instituição.

É preciso considerar, ainda, que quem fala sempre o faz de maneira posicionada. Ao ocupar o lugar de dirigente é, portanto, desse lugar que o entrevistado falará. Mas, se, ao contrário, o entrevistado estiver na oposição ao grupo que está no poder, será também desse lugar que ele relembrará o passado. Os conflitos, as posições, as dualidades são decorrentes de um lugar posicionado de onde sempre se produz os testemunhos. Há, portanto, enquadramentos da memória em função "dos combates do presente e do futuro" (POLLAK, 1989, p.10).

Feitas essas considerações em torno da complexa teorização da memória, há que se considerar as relações estreitas entre memória e comunicação. Materializada sempre por atos comunicacionais, em diálogos sempre corporais, a memória institui a existência do ser (RICOEUR, 2008) e produz as especificidades daquele que fala ao recordar o passado.

Mas não é apenas pelo gesto da fala que a memória se produz. Ela também se instaura no corpo, que deixa visível a passagem do tempo e a memória de uma vida, que de ativa se torna cambiante.

Nesse sentido, a memória invisível aparece no corpo envelhecido dos homens e mulheres, objeto dessa pesquisa, que partilham um lugar em comum, o do samba, construindo estratégias comunicacionais duradouras em torno desses lugares. Se a Associação que construíram é o lugar de institucionalização de sua fala como sambistas, por estratégias sensíveis, por afetos e partilhas de um mesmo mundo vão edificando em atos de comunicação cotidianos - a música, a dança, as festas, a instauração de símbolos do mundo da Velha Guarda, como a bandeira, as faixas demarcando os lugares que ocupam na hierarquia do samba, etc. - a memória duradoura do lugar que ocupam no mundo social.

No item seguinte, apresentaremos algumas das falas dos sambistas, que constroem a própria biografia atrelada ao mundo do samba. Pelos trabalhos da memória e por atos de comunicação inter-relacionam biografia e samba. 


\title{
Trabalhos da memória: biografias e o samba
}

\begin{abstract}
Meu pai era fundador da escola, mas meu pai era da bateria e minha mãe era baiana - ala das Sete Liras. Assim que fundou, foi fundada a ala das Sete Liras onde saía essa menina que não veio, a esposa dele [aponta para o I. S.], a que estava fazendo aniversário no domingo. Tinha ala que a mãe dela saía com a minha mãe. Está aqui [mostra as fotos que trouxe]. Eu, minha mãe, meu pai e minha cumadre (sic). A foto é de fevereiro de 69. Aqui eu estava com vinte e poucos anos, eu tinha casado, aí meu marido não deixava mais eu sair de ala, de coisa nenhuma. Aí eu estava grávida do meu filho. Saí de baiana, saí na ala de baiana junto com mamãe. Papai pediu para eu sair, novinha (M. R. T. Entrevista à autora em 21 de dezembro de 2011).
\end{abstract}

Na memória de M. R. T. ${ }^{6}$, vice-presidente da Velha Guarda da União de Jacarepaguá, destaca-se a construção da sua trajetória de vida misturada com a história da escola e com o samba. A maioria marca o início de sua vida pelo ingresso no samba: é como se já tivessem nascido dentro das quadras. Os seus pais se conheceram nas quadras e nos blocos. E, assim, constroem no discurso memorável suas trajetórias de vida sempre relacionadas ao universo do samba (conhecem, namoram e casam com integrantes das escolas). Ao falar sobre a vida, mesclam invariavelmente suas biografias com as histórias do mundo do samba.

Ao conversar com os três integrantes da AVGESRJ ao mesmo tempo, enquanto os mais falantes, como M. R. T. e I. S. dão detalhes minuciosos dos desfiles, das fantasias, dos lugares onde o samba existia no passado, a mais calada, M. S. F., apenas acrescentava uma frase aqui e ali para completar ou reafirmar o que os amigos diziam na entrevista. As lembranças de uns se completavam pelos trabalhos da memória de outros: um lembrava um aspecto, enquanto o outro completava aquilo que era dito com uma frase, uma expressão ou uma palavra. Há nessas experiências de memória uma economia da lembrança do grupo, que claramente aparece nas entrevistas quando realizadas em conjunto.

Optamos por usar nesse trabalho, de maneira concentrada, a única entrevista que realizamos em grupo com três integrantes da União de Jacarepaguá. Em grupo, os trabalhos de memória dos entrevistados ganham outra dimensão. A questão do testemunho partilhado aparece mais visivelmente, ao mesmo tempo em que pelos trabalhos de memória, cada um vai, paulatinamente, completando as lembranças do outro.

\footnotetext{
${ }^{6}$ Optamos por não revelar a identidade dos entrevistados, conforme orientação do Conselho de Ética dos cursos de pós-graduação da Universidade do Estado do Rio de Janeiro (UERJ), onde esta pesquisa foi realizada.
} 
Jogos articulados de linguagem vão compondo gradativamente memórias vivenciadas e partilhadas.

Ao relembrar que a iniciação no mundo do samba se fazia quando as crianças completavam sete anos de idade, M. R. T. dá detalhes singulares não apenas da maneira como os pequenos desfilavam, mas das sociabilidades que existiam entre vizinhos e parentes que tomavam conta das crianças, enquanto os mais velhos caíam no samba.

M. R. T.: é que a minha mãe saí e ela levava a gente. A gente ia crescendo e ela ia levando.

M. S. F.: no meu caso, era o meu pai [quem levava]. O meu pai era tesoureiro aí.

M. R.T.: enquanto estava pequenininho ela deixava, tinha uns vizinhos que ela deixava. O meu sogro ficava, todo mundo ficava, sabe. Mais vai crescendo, fazia sete anos ela botava [no samba]. Que antigamente tinha aquele negócio de sair de uniforme. Lembra?

M. S. F.: Uniforme.

Pesquisadora: Não tinha a ala das crianças?

M. R. T.: Antigamente tinha ala das crianças mas era de uniforme. Só saía de uniformezinho de escola [referindo-se ao uniforme da escola primária]. Então eu comecei com uniforme de escola, a gravatinha. Antigamente era a gravatinha. Aí comecei assim com sete anos, no Vai se Quiser, aí fundou a escola [de samba]. Aí quando eu fiz quinze anos, foi escolhidas as portas-bandeiras (sic). Porque antigamente era assim, a porta-bandeira tinha que ser da Escola (Entrevista à autora em 20 de dezembro de 2011).

$\mathrm{Na}$ fala dos entrevistados aparece também como um trabalho de reconstrução do passado a maneira como as crianças eram introduzidas no mundo do samba. Levados invariavelmente por um familiar próximo - M. R. T. é iniciada pela mãe, enquanto M. S. F., pelo pai -, a vida de cada um se confunde com a vida nas quadras das escolas de samba. Se até sete anos não era possível frequentá-las, depois iam passando de ala em ala até atingir o ponto culminante, que no caso de M. R. T. foi ter chegado a porta-bandeira. No jogo de lembrar e esquecer, ela também recorda hábitos já sepultados: o uniforme da escola pública que as crianças ostentavam no desfile. A informação tão distante obriga M. S. F. a confirmar o testemunho de M. R. T., repetindo a palavra "uniforme".

Os antepassados também aparecem com frequência como pessoas chaves no universo do samba: são fundadores, ocupam lugares de importância (ala dos compositores, integrantes da bateria, etc.) e vão passando de ala em ala, de acordo com a idade, até terminar na Velha Guarda, como já observamos anteriormente.

Os laços de amizade construídos no tempo e atravessando gerações - "tinha a ala que a mãe dela saía com a minha mãe" - surgem repetidamente na fala dos integrantes da Velha Guarda sempre quando é acionado o passado a partir do presente. É o fato de M. S. F. também estar presente na entrevista que aciona a memória de M. R. T. que, no presente da entrevista, lembra que a mãe dela saía com a mãe da outra. 
Considerando que, ao falar do passado, esses integrantes narram acontecimentos vividos, observamos também a mistura do presente no passado, e a apresentação de documentos que procuram atestar o passado como verdadeiro, como "relíquias da memória". As fotos que M. R. T. tira da sacola de papelão tornam o passado mais fiel para a pesquisadora que no presente tenta entender aquele universo. As fotos são a materialização da memória da entrevistada, que viveu aqueles acontecimentos por estar presente ou por ouvir contar, como no caso das lembranças das ações de seus pais.

M. R. T. chega para a entrevista maquiada, com o cabelo arrumado, vestindo uma bermuda jeans e uma camiseta. Na mão, a sacola com os restos da sua memória, de sua família, ou seja, do mundo do samba. As variáveis de ordem afetiva - interesse e sentimento - se mostram, de fato, como princípios generativos da memória. Havia uma ordem motivacional para ela: alguém queria que ela falasse da Associação, da Velha Guarda e de sua vida no mundo do samba. Ela sabia disso previamente. Havia também outra variável de ordem afetiva: o sentimento de M. R. T. (a saudade, a emoção, os momentos marcantes da sua vida) que vai acionando sua memória, produzindo lembranças e encobrimentos. Na construção sociocognitiva do mundo do samba, há “interesses moldáveis e sentimentos envolvidos” (SÁ, 2007, p. 292).

Então aí fez o sorteio e com quinze anos comecei a sair de porta-bandeira no Vai se Quiser. Aí quando teve a fundação foi em 56, em 57 aí eu estava noiva. Aí só saí um ano na União de Jacarepaguá de porta-bandeira. Porque aí meu noivo já não deixou mais, que é meu marido (risos). (M. R. T. Entrevista à autora em 20 de dezembro de 2011).

Ao relembrar a maneira como se escolha a porta bandeira, por sorteio, M. R. T. aciona sentimentos pessoais: o noivo, que depois virou marido, só a deixou ocupar um dos lugares mais importantes da escola por um ano. Por razões sentimentais, que ela não revela, o noivo "não deixou mais". O encobrimento memorável de M. R. T. aparece sob a forma de risos. Refletir sobre a relação memória e comunicação, portanto, é perceber também como os entrevistados narram os acontecimentos, mesclando sua vida ao mundo do samba.

Ah! Meu pai! [mostra a foto do pai]. Meu pai era o primeiro tamborim da escola [risos]. Papai só parou de sair quando morreu; no último ano ele saiu. Ele saiu em fevereiro de 1971 e em junho de 1971 ele faleceu. Logo depois daí [mostra a foto dela, ao lado da mãe e do pai no Carnaval de 1971]. Ele saía doente mesmo e não queria nem saber, batia tamborim até de manhã. Isso era na Rio Branco [mostra de novo a mesma foto tirada na Avenida Rio Branco] (M. R. T. Entrevista à autora em 20 de dezembro de 2011). 
A lembrança dos familiares mais próximos (o pai e a mãe) aparece misturada com a história da escola. A importância do pai, que era o primeiro tamborim de uma das alas mais conceituadas - a da bateria - é destacada, assim como a sua fidelidade à escola, representada pela ação de ter desfilado até o final da vida: “ele saiu em fevereiro de 1971 e em junho de 1971 ele faleceu".

A fidelidade e o amor à escola de samba, como que justificando o fato de poderem falar sobre o universo do samba, são marcas constantes nos fragmentos da memória, assim como as localizações da lembrança: os espaços onde a ação dos sambistas se realizavam (a Avenida Presidente Vargas, a Avenida Rio Branco no centro do Rio de Janeiro, neste caso, a Passarela do Samba, na Praça Onze) e os de fixação do tempo passado (as fotografias como imobilização do passado).

No pequeno trecho da entrevista, observamos que duas vezes a sambista mostra a mesma foto: na primeira vez para indicar a fidelidade de seu pai à escola, atestando ser aquele, de fato, o carnaval de 1971, que se junta à informação dela de que ele morreu quatro meses depois. Na segunda vez, a mesma foto serve para indicar que o desfile daquela escola se realizara, naquele ano, na Avenida Rio Branco ${ }^{7}$.

Observamos também que esses fragmentos se transformam em narrativas, com começo, meio e fim, quando a memória de um integrante completa a do outro. Ao perguntar detalhes sobre os desfiles, especialmente sobre o tempo que durava a apresentação das escolas, os três componentes participam ao mesmo tempo da entrevista, cada um fornecendo detalhes específicos sobre o passado. Tudo sob a forma de fragmentos:

\footnotetext{
Pesquisadora: O desfile durava quanto tempo na Avenida Rio Branco? Tinha um tempo certo para durar?

M. R. T.: Não tinha um tempo certo, certinho assim não tinha não.

M. S. F.: Agora se passar 10 minutos você perde ponto. Antes a gente passava quase meia hora e não tinha problema.

Pesquisadora: E dava para sambar?

M. R. T. e I. S.: Dava para sambar. Agora não dá mais não.

M. S. F.: Você ia lá na frente, voltava cá atrás. Agora não.

M. R. T.: E você não pode voltar.

I. S.: Agora não pode voltar mais não, tem que ir pra frente (Entrevista à autora em 20 de dezembro de 2011).
}

Nas respostas dos três integrantes, observamos que eles percebem o passado como sendo um tempo melhor, sobretudo, porque permitia a experiência da liberdade no

\footnotetext{
${ }^{7}$ Na década de 1970, havia desfiles de escolas de samba no Rio de Janeiro tanto na Avenida Presidente Vargas, como na Avenida Rio Branco. No primeiro logradouro desfilavam as escolas mais importantes, e na Avenida Rio Branco aquelas que eram conhecidas como sendo do segundo grupo.
} 
cotidiano de cada um. $\mathrm{O}$ fato de não estarem, no passado, submetidos às regras de tempo ("não tinha um tempo certo, certinho assim não tinha não"; "agora se passar 10 minutos você perde ponto" ou "antes a gente passava quase meia hora e não tinha problema") e de espaço ("você ia lá na frente, voltava cá atrás, agora não") significa para eles a experiência da liberdade. No exercício da lembrança sobressai então a descrição dos desfiles não submetidos às normas da Liga das Escolas de Samba (LIESA) como sendo um tempo melhor. A rigidez do horário (cada escola tem até 50 minutos para percorrer o Sambódromo no Rio de Janeiro) e os lugares nas alas, tudo milimetricamente cronometrado como deve ser numa indústria, representam a impossibilidade de apresentar o que de fato sabem fazer: sambar.

\section{Considerações finais}

Nos fragmentos narrativos que apresentamos neste texto observa-se também a existência de um acordo tácito para falar da mesma coisa: todos ao lembrar criticam as regras atuais dos desfiles das escolas de samba. Nessa crítica aparece com nostalgia a referência ao lugar da Velha Guarda na hierarquia das escolas e que se materializa na ordem do desfile, já referida anteriormente.

$\mathrm{Na}$ operação memorável, o que se lembra aparece sob a forma de fragmentos, sendo a narrativa a maneira de ligar pontos da lembrança dando coerência à forma como se conta aquela história. Se considerarmos que narrar é mais do que contar uma história, sendo, como enfatiza Paul Ricoeur (1997), uma forma de ação humana capaz de tornar o mundo inteligível, através do que ele conceitua como "atividade mimética" que atua sobre o tempo e produz um discurso unificado, a relação memória e narrativa, como vida e atos de comunicação, se torna ainda mais próxima.

Pela memória produzo uma ação mimética do passado, ou seja, o passado verdadeiro torna-se aquele do qual eu sou testemunha: não existe mais o passado, mas apenas fragmentos da minha memória que pela narrativa se transforma no passado. Nos testemunhos do passado, o autor da lembrança fala no presente contando o que ocorreu no passado e é sua voz narrativa que constrói o passado. Os acontecimentos relatados também pertencem ao passado daquela voz.

Através das narrativas conhecemos mais do que as histórias dessas pessoas que ajudaram a construir a história do samba do Rio de Janeiro: conhecemos o seu mundo narrativo e as marcas das partilhas de um mundo sensível que se instaura a partir de atos 
de comunicação. Se narrar é construir a existência, ao rememorar o passado através do ato narrativo, esses atores se colocam no mundo por este ato.

(Artigo recebido em 21/07/2013, aprovado em 04/08/2013)

\section{Referências}

BERGSON, Henri. Matéria e memória: Ensaio sobre a relação do corpo com o espírito. São Paulo: Martins Fontes, 1990.

BOSI, Ecléa. Memória e sociedade: Lembranças de Velhos. São Paulo: Companhia das das Letras, 1994.

BOURDIEU, Pierre. O poder simbólico. Lisboa: Difel, 1989.

CANDAU, Joël. Memória e identidade. São Paulo: Contexto, 2011.

COLOMBO, Fausto. Os arquivos imperfeitos. São Paulo: Perspectiva, 1991.

FREUD, Sigmund. Recordar, repetir e elaborar (1914) e Notas sobre o Bloco Mágico (1925). Obras completas. CD-Rom. Edição Eletrônica Brasileira das Obras Psicológicas Completas de Sigmund Freud. Rio de Janeiro: Imago Editora, s/d.

HALBWACHS, Maurice. A memória coletiva. São Paulo: Centauro, 2006.

HUYSSEN, Andreas. Seduzidos pela memória. Rio de Janeiro: Artiplano, 2000.

JAMESON, Fredric. Espaço e imagem: teorias do pós-moderno e outros ensaios de Fredric Jameson. Rio de Janeiro: Editora UFRJ, 2006.

NORA, Pierre. Les lieux de mémoire. Paris: Gallimard, 1984, vol. 1.

POLLAK, M. Memória e identidade social. Revista Estudos Históricos, v. 5, nº 10, 1992. Rio de Janeiro: CPDOC, FGV, p. 200-212.

POLLAK, M. Memória, esquecimento, silêncio. In: Revista Estudos Históricos, Vol. 2, $\mathrm{N}^{\circ} \quad 3$ 1989. Rio de Janeiro: CPDOC, FGV. http://bibliotecadigital.fgv.br/ojs/index.php/reh/article/viewArticle/2278

RANCIÈRE, Jacques. A partilha do sensível. São Paulo: Editora 34, 2009.

RIBEIRO, Ana Paula Goulart e BRASILIENSE, Danielle Ramos. Memória e narrativa jornalística. In: RIBEIRO, Ana Paula Goulart e FERREIRA, Lúcia Maria Alves (org.). Mídia e memória. A produção de sentidos nos meios de comunicação. Rio de Janeiro: Mauad, 2007, p. 219-236.

RICOEUR, Paul. A memória, a história, o esquecimento. Campinas: UNICAMP, 2008.

SÁ, C. P. Sobre o campo de estudo da memória social: uma perspectiva psicossocial. In: Psicologia: Reflexão e Crítica, v.20, n.2, 2007, p.290-295.

WEINRICH, Harald. Lete: Arte e crítica do esquecimento. Rio de Janeiro: Civilização Brasileira, 2001. 